\title{
INVESTIGATION OF IDIOPATHIC PLEURAL EFFUSIONS BY THORACOSCOPY
}

\author{
BY \\ S. J. FLEISHMAN, A. I. LICHTER, G. BUCHANAN, AND R. J. S. SICHEL \\ From the Silicosis Medical Bureau and the South African Institute for Medical Research, Johannesburg, \\ South Africa
}

(RECEIVED FOR PUBLICATION MARCH 26, 1956)

The African labour force employed by the goldmining industry in South Africa is recruited from an area covering the whole sub-continent from Tanganyika in the north to the Transkei in the Cape Province. The majority of these labourers are migrants, returning home for varying lengths of time between periods of mine service, which on the average last two years. Any African mine labourer suspected of suffering from silicosis or respiratory tuberculosis is transferred to a central hospital in Johannesburg for further investigation, because sufferers from these diseases are compensated in terms of the Union Silicosis Act.

Pleural effusion is one of the more common conditions that we have encountered in these labourers, whereas it is comparatively rare among white gold-miners. In the absence of evidence to the contrary, such lesions are usually regarded as being of tuberculous aetiology. Nevertheless, the number of pleural fluids that in our experience yielded tubercle bacilli on direct, cultural, or biological examination was negligible. We were prompted, therefore, to submit a number of cases of pleural effusion to thoracoscopic examination, in order to determine whether this procedure could assist us in arriving at an accurate diagnosis. When this investigation was planned the work of Lloyd (1953) had not yet been published. He thoracoscoped 23 consecutive cases of pleural effusion and found that the majority of them had a neoplastic basis, only one proving to be tuberculous. Fabri and Parmeggiani (1942) had also used this method of investigation, and reported their observations in 10 cases of suspected tuberculous effusion.

A total of 276 cases of pleural effusion were seen between March, 1953, and May, 1955, but only 76 of these were eventually thoracoscoped. Two hundred were not examined by this method for the following reasons : effusion too small for safety (93); procedure refused (32); evidence of

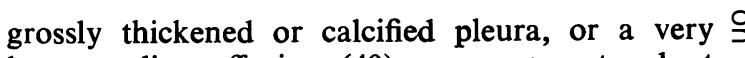
long-standing effusion (40); pus encountered at preliminary paracentesis (5); associated pneumothorax (4); patient too ill (2) ; rapidly clearing, presumably post-pneumonic effusion (12); no record of reason (12).

All cases thoracoscoped were Mantoux tested with $0.1 \mathrm{ml}$. of $1 / 1,000 \mathrm{Koch}$ 's old tuberculin, and, in all but one, a positive reaction was elicited. In no case did the physical examination give an indication of the cause of the effusion. Hepatomegaly and splenomegaly were frequently noted, but these findings in the Africans are too common to be helpful in determining the aetiology of pleural effusions. Albuminuria was not encountered. The chest radiographs suggested pericarditis on four occasions, and, in these, $\mathrm{T}$-wave changes compatible with this diagnosis were found on the electrocardiograms. In one case only was there radiographic evidence of a parenchymal tuberculous lesion (a minimal apical focus), and in no instance of hilar adenopathy.

\section{METHOD}

After aspirating the fluid in the pleural space, $\frac{7}{7}$ thoracoscopy was carried out under local anaesthesia in the usual manner. Where massive effusions were present, two or more aspirations at intervals of a few $\mathrm{N}$ days were necessary. The fluid was sent for examina- $N$ tion for the presence of tubercle bacilli by direct, cul- $N$ tural, and biological methods, and for investigation of $\omega$ its cytology. The thoracoscope was then inserted and the pleural space inspected. Biopsies were takeno from the most abnormal-looking areas (see thoracoscopic findings below), using a direct-vision thoracoscope and a biopsy forceps through a second trocar and cannula.

Biopsy specimens were examined histologically and stained for tubercle bacilli. Special preparations of $\frac{\rho}{\mathbb{Q}}$ tissue were submitted to cultural examination and also을 injected into guinea-pigs. 


\section{The Preparation of Pleural Biopsy Specimens For Culture and ANimal InOCulation}

The specimens were ground in a sterile mortar and subjected to treatment based on Petrof's method, i.e., a volume of $4 \%$ sodium hydroxide approximately four times that of the specimen was added, a little at a time, and mixed with the ground tissue. The suspensions were incubated at $37^{\circ} \mathrm{C}$. for not more than 30 minutes, then neutralized with $4 \%$ hydrochloric acid, litmus paper being used as indicator. The tissue suspensions were transferred to sterile tubes, centrifuged, and the supernatant fluid withdrawn. Part of the sediment was inoculated into Löwenstein-Jensen and Youman's media and the remainder into the right groin of guinea-pigs.

The earlier biopsies were examined histologically and stained for alcohol and acid-fast bacilli only. The later specimens were also examined by the above method, in several instances specimens from both visceral and parietal pleura from the same case being submitted. A total of 65 pleural biopsies were dealt with in the above manner. The cultures were kept under observation for two months unless growth was shown earlier. The guinea-pigs were submitted to necropsy when they presented palpable swellings in the right groin or after a two-month period of observation. Of the 65 specimens examined, 12 produced tuberculosis in guinea-pigs, i.e., $18.4 \%$. Ten of these gave a growth of $M$. tuberculosis of the human type on culture. In the two cases in which culture gave no growth but guinea-pig inoculation showed the presence of tubercle, specimens taken from the guineapig lesions were subsequently cultured and a growth of the human type of $M$. tuberculosis was obtained.

\section{Thoracoscopic Findings}

In the majority of cases the space was found to be loculated and the parietal pleura thickened, red, and oedematous. The pleura was usually covered with a membranous layer of fibrin, which histologically often proved to be organizing granulation tissue. Occasionally a portion of this membrane could be pulled off, leaving the normal glistening pleura visible beneath. In only a few instances was this layer absent, thus allowing a view of the true pleura. Numerous sheets of filmy adhesions frequently filled the space; more rarely, fleshy adhesions were present, resembling those found when thoracoscoping cases of artificial pneumothorax. Masses of pale grey gelatinous material were often present, and fibrinous deposits were also encountered. These adhesions and masses frequently prevented a comprehensive view of the pleura, and sometimes made it quite impossible to visualize the pleural surfaces at all. White spots, 1-2 $\mathrm{mm}$. in diameter, were sometimes seen in the membranous layer lining the space; less frequently, larger white plaques were present, and, rarely, tubercles appeared as rounded elevations. Irregular subpleural haemorrhages of varying size were also seen.

Biopsies could readily be taken from the thickened pleura, the membrane overlying the visceral pleura, and from intrapleural adhesions and gelatinous masses.

\section{RESULTS}

The effusion was right-sided in two-thirds of the 76 cases thoracoscoped (bilateral in one case only) and was blood-stained in varying degree in a third. No biopsies were taken from five of the earlier cases thoracoscoped. Of the remaining 71 cases, examination of the biopsy material, either by

TABLE

DIAGNOSTIC EVIDENCE FOR TUBERCULOSIS ON EXAMINATION OF PLEURAL BIOPSY SPECIMENS IN 22 PROVED CASES

\begin{tabular}{|c|c|c|c|c|}
\hline $\begin{array}{l}\text { Case } \\
\text { No. }\end{array}$ & $\begin{array}{c}\text { Histological } \\
\text { Evidence of } \\
\text { Tubercle }\end{array}$ & $\begin{array}{c}\text { Stain for } \\
\text { Acid- and } \\
\text { Alcohol-fast } \\
\text { Bacilli } \\
\text { Positive }\end{array}$ & $\begin{array}{l}\text { Culture of } \\
\text { Biopsy } \\
\text { Specimen } \\
\text { Positive for } \\
\text { Tubercle }\end{array}$ & $\begin{array}{c}\text { Biological } \\
\text { Test on Biopsy } \\
\text { Specimen } \\
\text { Positive for } \\
\text { Tubercle }\end{array}$ \\
\hline $\begin{array}{l}1 \\
2 \\
3 \\
4 \\
5 \\
6 \\
7 \\
8 \\
9 \\
10 \\
11 \\
12 \\
13 \\
14 \\
15 \\
16 \\
17 \\
18 \\
19 \\
20 \\
21 \\
22\end{array}$ & 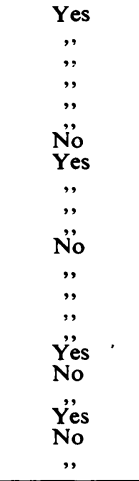 & $\begin{array}{c}\text { Yes } \\
\text { No } \\
\text { Yes } \\
, " \\
\text { No } \\
\text {,' } \\
\text {,' } \\
\text { ", } \\
\text { Yes } \\
\text { No } \\
\text { Y'es } \\
\text { No } \\
\text {, } \\
\text { Yes } \\
\text { No }\end{array}$ & $\begin{array}{c}\text { Not done } \\
\text { ", ", } \\
\text { "Yes } \\
\text { No } \\
\text { Not done } \\
\text { Yes } \\
\text { No } \\
\text {," } \\
\text { Yes } \\
\text {," } \\
\text { ", } \\
\text { No } \\
\text { Yes } \\
\text { No } \\
\text { Yes } \\
\text { No } \\
\text { Yes } \\
\text {," }\end{array}$ & $\begin{array}{c}\text { Not done } \\
\text {, ", } \\
\text {, Yes } \\
\text { No } \\
\text { Not done } \\
\text { Yes } \\
\text { No } \\
\text { ", } \\
\text { Yes } \\
\text { " } \\
\text { No } \\
\text { Yes } \\
\text { ", } \\
\text { ", } \\
\text { ", }\end{array}$ \\
\hline Total & 12 & 7 & 10 & 12 \\
\hline
\end{tabular}

histological or cultural and biological methods, enabled a positive diagnosis of tuberculosis (see Table) to be made in $22(31 \%)$. Positive results were obtained with equal frequency from parietal and visceral pleura, and occasionally from adhesions and gelatinous deposits in the pleural space. Although the pleural exudate was examined for tubercle bacilli by cultural and biological methods in all 76 cases, in only three were positive results obtained. In two of these evidence of tuberculosis was found at thoracoscopy. The sputum in another three cases revealed tubercle bacilli, and in two of these the pleural biopsy was positive.

Four patients subsequently died, for reasons not related to the thoracoscopy. Two had shown no evidence of tuberculosis by our method, and 
necropsy confirmed this. In a third case, although no overt tuberculosis could be detected at necropsy, histological examination of the pleura showed " one or two small foci of active tuberculosis in lung and pleura," although we had failed to find evidence of tuberculosis at thoracoscopy. This was one of our earlier cases in which biopsy specimens were not submitted to cultural and biological examination, and, incidentally, was the only patient in the series in whom the Mantoux test was negative. In the fourth case both biopsy and necropsy showed pleural tuberculosis.

In five cases the thoracoscopic appearances resembled those usually found at operation when decorticating an early clotted haemothorax, and in none of these was evidence of tuberculosis obtained. Although the histories given by our patients were notoriously unreliable, direct questioning revealed a previous history of chest injury in three of these five. Conversely, deeply bloodstained effusions were present in some cases that eventually proved to be tuberculous in origin; in these the appearances were not those of a clotted haemothorax.

This investigation failed to give proof of any diagnosis other than that of tuberculosis. In particular, carcinoma of the lung, which is relatively infrequent in the African, was not encountered.

\section{Discussion}

When this investigation was planned, it was hoped that the information obtained would make it possible to recognize tuberculous effusions at thoracoscopy without resorting to biopsy specimen examination. However, it was found that no single thoracoscopic finding, or combination of findings, could be relied upon when attempting to forecast the cause of the effusion. The cytology of the fluid also proved to be of no value.

Nevertheless, the white spots in the membrane, previously mentioned, indicated a tuberculous aetiology in most instances where they were seen ; indeed a histological diagnosis of tuberculosis could rarely be made where these were not present. On several occasions biopsies taken $1 \mathrm{~cm}$. distant from such lesions proved to be negative when the spots themselves contained histological evidence of tuberculosis. Examination of tissue other than these white spots was only of value with respect to cultural and biological tests for tubercle bacilli.

Of the cases thoracoscoped, a diagnosis of tuberculosis could have been made by sputum examination in three, and by bacteriological examination of the pleural fluid in another three.
The thoracoscopy did not show the presence of tubercle in two of these six cases. One of the four cases submitted to necropsy was also proved tuberculous where thoracoscopy had failed to give the diagnosis. These three cases, where the diagnosis was demonstrated by other methods, bring the figure for tuberculous effusions in the series to $35 \%$. If the cases where the diagnosis could have been established by conventional methods are excluded, we find that in $28 \%$ of the remainder no method other than pleural biopsy indicated the tuberculous aetiology of the effusion.

It is probable that the real incidence of tuberculous effusions is higher than these results show, because adhesions and gelatinous deposits in the pleural space frequently limited the view and precluded the accurate selection of biopsy sites, especially with regard to the white pleural spots. Again, although all the material sent for histological examination was embedded, only three or four sections from each block so made could be examined. Small lesions may therefore have been missed. This random sampling, employed because complete examination of serial sections was impracticable, may also account for the observation that tubercle bacilli were sometimes seen where the typical follicle formation and giant-cell systems of tuberculosis were not demonstrated, and vice versa. Similarly, owing to the smallness of the lesions, the portion of the biopsy specimen

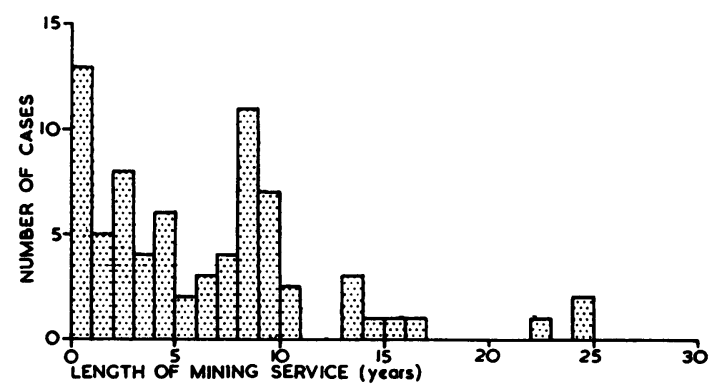

FIG. 1.-Diagram showing length of mining service of 71 African miners presenting with "idiopathic" pleural effusions.

submitted to bacteriological examination may

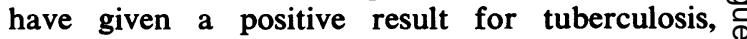
whereas that portion used for histological exami- ? nation may not have done so.

The mean length of mining service (Fig. 1) of our patients with proved tuberculous effusions was eight years (range, eight months to 25 years and 9 months). This was unexpected in view of the commonly accepted belief that primary tuberculous 
pleural effusions occur at, or shortly after, the time of the primary infection. It seems unlikely that the primary infection should have occurred after so long a time, when conditions are such that early infection is highly probable.

The Northern Rhodesia Silicosis Medical Bureau (1955) have been able to follow up for five years, both clinically and radiologically, a large number of cases of pleural effusion in African mine labourers. Only one of these cases subsequently developed pulmonary tuberculosis. This and other investigations led them to believe that the majority of their cases were not tuberculous in origin. We are not in a position to carry out such follow-up studies, because our patients on leaving Johannesburg are dispersed over most of South Africa. Our findings are not in keeping with those of the Northern Rhodesia Silicosis Medical Bureau, and are more in agreement with the well-known observations of Thompson (1946) and the more recent paper by Roper and Waring (1955) that a high proportion of idiopathic effusions are tuberculous in nature.

\section{CONCLUSIONS}

Seventy-one cases of "idiopathic" pleural effusion were thoracoscoped and biopsies of the pleura taken in an effort to establish the aetiology of the effusion.

Thirty-one per cent. were proved by this method to be tuberculous.

In $4 \%$ of the cases, where pleural biopsy was negative, the tuberculous nature of the effusion was proved by either sputum examination, bacteriological examination of the fluid, or necropsy.
The total figure for tuberculous effusions in the series is therefore $35 \%$.

Excluding the cases in which the diagnosis could have been made by other means (sputum examination, cultural and biological examination of the pleural fluid, etc.) a diagnosis of tuberculosis was made by thoracoscopy in $28 \%$ of pleural effusions where no other method of investigation was of assistance.

We wish to thank the Honourable the Minister of Mines for permission to publish this paper. We are indebted to Dr. Frank Retief, Chief Medical Officer of the Witwatersrand Native Labour Association Hospital, for his kind co-operation; to the medical and nursing staff of that hospital for their invaluable assistance in this investigation. We wish to acknowledge our indebtedness to Dr. H. W. Alberts and Dr. T. von Haebler, of the Bacteriology Department of the South African Institute for Medical Research, for undertaking the examination of the pleural fluids. The pathological services of the Institute were placed at our disposal by Dr. J. F. Murray, Superintendent of the Diagnostic Department. We wish to place on record our appreciation of his help and constructive criticism.

We have much pleasure in thanking Brigadier W. $\mathbf{H}$. du Plessis, O.B.E., Chairman of the Silicosis Medical Bureau, for his advice and encouragement in planning and organizing this investigation.

\section{REFERENCES}

Fabri, G., and Parmeggiani, D. (1942). Policlinico, Sez. prat., 48, 1347.

Lloyd, M. S. (1953). Quart. Bull. Sea View Hosp., 14, 128.

Northern Rhodesia Silicosis Medical Bureau (1955). Annual Report for the Year 1954. Government Printer, Lusaka.

Roper, W. H., and Waring, J. J. (1955). Amer. Rev. Tuberc., 71, 616.

Thompson, B. C. (1946). Ibid., 54, 349. 